\title{
Biomarkers that predict attacks of acute intermittent porphyria
}

\author{
Tadayuki Takata ${ }^{1,2}$, Asahiro Morishita ${ }^{3}$, Hideki Kobara ${ }^{3}$, Kazushi Deguchi ${ }^{2}$, Tsutomu Masaki ${ }^{3}$ \\ ${ }^{1}$ Department of Supportive and Promotive Medicine of the Municipal Hospital, Kagawa University Faculty of Medicine, Miki, Japan; ${ }^{2}$ Department \\ of Neurology, Kagawa University Faculty of Medicine, Miki, Japan; ${ }^{3}$ Department of Gastroenterology, Kagawa University Faculty of Medicine, Miki, \\ Japan \\ Correspondence to: Tadayuki Takata, MD, PhD. Department of Supportive and Promotive Medicine of the Municipal Hospital, Kagawa University \\ Faculty of Medicine, 1750-1 Ikenobe, Miki-Cho, Kita-Gun, Kagawa 761-0793, Japan. Email: takata.tadayuki@kagawa-u.ac.jp.
}

Received: 17 April 2021; Accepted: 22 June 2021; Published: 25 October 2022.

doi: $10.21037 /$ tgh-21-50

View this article at: https://dx.doi.org/10.21037/tgh-21-50

We appreciate that Dr. Bruce Wang agrees with us regarding the importance of identifying known triggers of acute attacks in acute intermittent porphyria (AIP) (1). AIP is a recurrent disease associated with severe abdominal pain, peripheral neuropathy, and central or autonomic nervoussystem manifestations (2). Certain drugs and menstruation are known factors that can induce acute attacks (2). If acuteattack symptoms are not treated, they may become severe and the patient may require hospitalization (3). Although porphyria can be detected by measuring urine and stool porphyrin precursors (2), measuring porphyrin precursors does not help predict aggravation, as they can continuously increase in AIP, as demonstrated in a previous report (4). To our knowledge, no serological biomarkers for the prediction of acute attacks in AIP have been reported in post-diagnosis management. We herein discuss blood-test parameters that correlate with urinary porphyrin precursors and examine which parameters may be indicators of an acute attack. We experienced only one case; however, we obtained long-term data from the case reported here.

The patient in this case was a 20 -year-old woman with acute onset AIP. She was intravenously administered $3-4 \mathrm{mg} / \mathrm{kg}$ of heme arginine acid (HA) almost monthly for 6 years because of acute attacks associated with her menstrual cycle. We previously reported the clinical course of this case (3). All 51 datasets consisting of blood and urine test results between November 7, 2014, and November 30,2020 , were analyzed in a retrospective study. As HA was administered for acute attacks, post-administration data were not included to avoid the direct effects of HA. The datasets were divided into three groups according to the clinical state during sampling: stable (asymptomatic, which is synonymous with non-attack), mild acute attack (abdominal distension and constipation), and severe acute attack (pain, tachycardia, hypertension, and seizures). Datasets were analyzed for stable periods and before HA administration in mild and severe acute attacks. The measured parameters were urinary delta-aminolevulinic acid (U-SALA) [normal value $<3 \mathrm{mg} / \mathrm{g}$ creatine $(\mathrm{Cr})$ ], urinary porphobilinogen (U-PBG) (normal value $<2 \mathrm{mg} / \mathrm{g} \mathrm{Cr}$ ), complete blood cell count, serum blood urea nitrogen (BUN), Cr, uric acid (UA), total bilirubin (Tbil), aspartate aminotransferase (AST), alanine aminotransferase (ALT), alkaline phosphatase, lactate dehydrogenase, $\gamma$-glutamyl transpeptidase, sodium $(\mathrm{Na})$, potassium $(\mathrm{K})$, chloride $(\mathrm{Cl})$, total cholesterol, triglyceride (TG), low-density lipoprotein (LDL), and ferritin. Pearson's correlation coefficients were calculated for the above data. The Tukey-Kramer method was used to compare whether the parameters that correlated with porphyrin precursors were significantly different in the stable, mild acute-attack, and severe acute-attack groups. Statistical analyses were performed using SPSS (ver. 26; IBM, Armonk, NY, USA).

U- $\delta$ ALA was correlated with U-PBG $(\mathrm{P}<0.001$, $|\mathrm{r}|=0.723)$, Tbil $(\mathrm{P}=0.014,|\mathrm{r}|=0.341)$, and serum $\mathrm{Na}$ $(\mathrm{P}<0.001,|\mathrm{r}|=0.492)$ [Figure $1 A(i, i i, i i i)$ ]. U-PBG was correlated with $\mathrm{UA}(\mathrm{P}=0.005,|\mathrm{r}|=0.406)$ and serum $\mathrm{Na}$ $(\mathrm{P}=0.033,|\mathrm{r}|=0.299)$ [Figure $1 A(i v, v)$ ]. A correlation was also found between U- $\delta$ ALA and TG (triglyceride) $(\mathrm{P}=0.033,|\mathrm{r}|=0.315)$ and $\mathrm{U}-\mathrm{PBG}$ and LDL $(\mathrm{P}=0.030$, $|\mathrm{r}|=0.474)$, but the postprandial blood tests showed mixed results. There was no correlation between other parameters and urinary porphyrin precursors. Urinary porphyrin precursors did not necessarily show clinical symptoms 

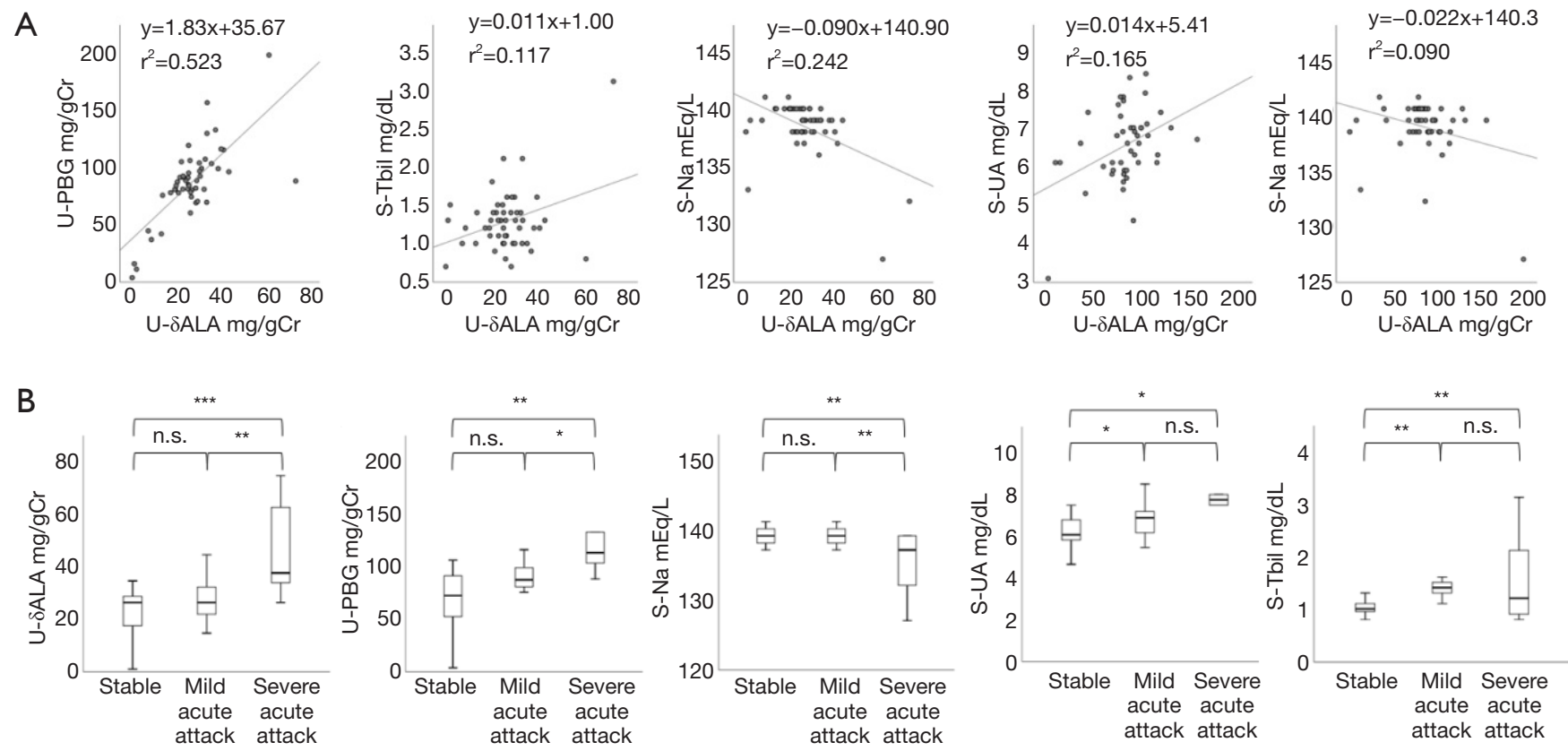

Figure 1 Blood parameters correlated with porphyrin precursors and comparison of data according to clinical state. (A) Statistical comparison using Pearson's correlation coefficient of: (i) U- $\delta$ ALA and U-PBG $(\mathrm{P}<0.001,|\mathrm{r}|=0.723)$; (ii) U- $\delta$ ALA and S-Tbil (P=0.014, $|\mathrm{r}|=0.341)$; (iii) $\mathrm{U}-\delta \mathrm{ALA}$ and $\mathrm{S}-\mathrm{Na}(\mathrm{P}<0.001,|\mathrm{r}|=0.492)$; and (iv) U-PBG and $\mathrm{S}-\mathrm{UA}(\mathrm{P}=0.005,|\mathrm{r}|=0.406)$, (v) U-PBG and S-Na (P=0.033,

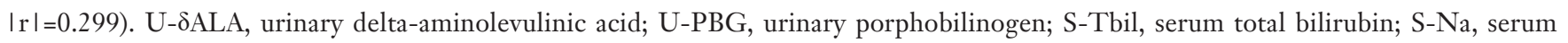
sodium; S-UA, serum uric acid. (B) Statistical comparison using the Tukey-Kramer method of clinical state of: (i) U- $\delta A L A$, (ii) U-PBG, (iii) $\mathrm{S}-\mathrm{Na}$, (iv) S-UA, and (v) S-Tbil. (i) $\mathrm{n}=16$, stable; $\mathrm{n}=29$, mild acute attack; $\mathrm{n}=6$, severe acute attack; $\mathrm{F}_{2,48}=9.537, \mathrm{P}<0.001$; stable $v$ s. mild acute attack, $\mathrm{P}=0.448$; mild acute attack vs. severe acute attack, $\mathrm{P}=0.001$; stable $v s$. severe acute attack, $\mathrm{P}<0.001$. (ii) $\mathrm{n}=16$, stable; $\mathrm{n}=29$, mild acute attack; $\mathrm{n}=6$, severe acute attack; $\mathrm{F}_{2,48}=8.178, \mathrm{P}=0.001$; stable $v$ s. mild acute attack, $\mathrm{P}=0.110$; mild acute attack vs. severe acute attack, $\mathrm{P}=0.017$; stable $v s$. severe acute attack, $\mathrm{P}=0.001$. (iii) $\mathrm{n}=16$, stable; $\mathrm{n}=29$, mild acute attack; $\mathrm{n}=6$, severe acute attack; $\mathrm{F}_{2,48}=8.947, \mathrm{P}<0.001 ;$ stable $v$ s. mild acute attack, $\mathrm{P}=0.942$; mild acute attack vs. severe acute attack, $\mathrm{P}=0.001$; stable $v s$. severe acute attack, $\mathrm{P}=0.001$. (iv) $\mathrm{n}=15$, stable; $\mathrm{n}=29$, mild acute attack; $\mathrm{n}=2$, severe acute attack; $\mathrm{F}_{2,43}=5.640, \mathrm{P}=0.007$; stable $v$ s. mild acute attack, $\mathrm{P}=0.019$; mild acute attack $v$. severe acute attack, $\mathrm{P}=0.359$; stable vs. severe acute attack, $\mathrm{P}=0.039$. (v) $\mathrm{n}=16$, stable; $\mathrm{n}=29$, mild acute attack; $\mathrm{n}=6$, severe acute attack; $\mathrm{F}_{2,48}=9.187$, $\mathrm{P}<0.001$; stable $v s$. mild acute attack, $\mathrm{P}=0.001$; mild acute attack $v$ s. severe acute attack, $\mathrm{P}=0.596$; stable vs. severe acute attack, $\mathrm{P}=0.004$. U- $\delta$ ALA, urinary delta-aminolevulinic acid; U-PBG, urinary porphobilinogen; S-Na, serum sodium; S-UA, serum uric acid; S-Tbil, serum total bilirubin; n.s., not significant. $\left({ }^{*} \mathrm{P}<0.05,{ }^{* *} \mathrm{P}<0.005\right.$, $\left.{ }^{* * *} \mathrm{P}<0.001\right)$.

even if the levels exceeded the normal range, but urinary porphyrin precursor levels significantly increased during severe acute attacks [Figure 1B(i,ii)]. Na showed significant decrease during severe acute attacks but did not show any significant difference during mild acute attacks compared to the stable-period values [Figure 1B(iii)]. UA and Tbil showed significant differences between stable and mild acute attacks, but not between mild acute and severe acute attacks [Figure $1 B(i v, v)]$. The total dose of HA was $11,275 \mathrm{mg}$ over 2,189 days, but no increase in ferritin was observed $(\mathrm{n}=35$, mean $91.5 \pm 36.7 \mathrm{ng} / \mathrm{mL})$. Most samples were collected 5 days before and after ovulation.
It has been reported that clinical symptoms do not always appear when the urinary porphyrin precursor level exceeds

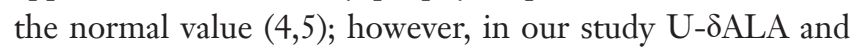
U-PBG increased as the severity of the attacks increased. Although no previous reports have shown that Tbil and UA increase during an attack, we found that elevated Tbil and UA could help predict mild acute attacks. The correlation between UA levels and renal function and between Tbil and liver damage remained unclear in our dataset. We previously proposed that systemic vascular spasm due to deficiency of nitric oxide synthase occurs in porphyria (3), but it was difficult to prove this etiology. If mild ischemia 
occurs in remission, blood tests may not show liver damage with elevated AST or ALT levels or renal dysfunction with elevated BUN or Cr levels.

In our dataset, the $\mathrm{Na}$ level significantly decreased during severe acute attacks, but we consider this to be inevitable because the inappropriate secretion of antidiuretic hormone is known to be complicated when porphyria becomes severe with acute attacks (6). $\mathrm{Na}$ is a predictor for severe acute attacks but was not a predictor for mild acute attacks in our dataset. Although the use of high-dose HA is known to be a risk factor for iron overload (7), we observed no obvious adverse events. Further, mild acute attacks remained in remission with $\mathrm{HA}(3 \mathrm{mg} / \mathrm{kg} /$ day). A limitation of the study is that the data analyzed between groups were unequal, as most consultations occurred during the stable or mild acuteattack periods. It may be possible to predict mild acute attacks using Tbil and UA. The mechanism of bilirubin and UA level elevation may involve insufficient synthesis of heme promoting the destruction of erythrocytes in the reticuloendothelial system, resulting in an increase in bilirubin and UA levels. There are a few reported cases of AIP with recurrent severe acute attacks; however more data are required in the future for further insight. Our report shows that an acute attack of AIP can potentially be predicted with a simple blood test.

\section{Acknowledgments}

The authors thank the patient for her cooperation. Funding: None.

\section{Footnote}

Provenance and Peer Review: This article was a standard submission to the journal. The article did not undergo external peer review.

Conflicts of Interest: All authors have completed the ICMJE uniform disclosure form (available at https://tgh.amegroups. com/article/view/10.21037/tgh-21-50/coif). The authors have no conflicts of interest to declare.

doi: $10.21037 /$ tgh-21-50

Cite this article as: Takata $\mathrm{T}$, Morishita A, Kobara H, Deguchi K, Masaki T. Biomarkers that predict attacks of acute intermittent porphyria. Transl Gastroenterol Hepatol 2022;7:44.
Ethical Statement: The authors are accountable for all aspects of the work in ensuring that questions related to the accuracy or integrity of any part of the work are appropriately investigated and resolved.

Open Access Statement: This is an Open Access article distributed in accordance with the Creative Commons Attribution-NonCommercial-NoDerivs 4.0 International License (CC BY-NC-ND 4.0), which permits the noncommercial replication and distribution of the article with the strict proviso that no changes or edits are made and the original work is properly cited (including links to both the formal publication through the relevant DOI and the license). See: https://creativecommons.org/licenses/by-nc-nd/4.0/.

\section{References}

1. Wang B. The acute hepatic porphyrias. Transl Gastroenterol Hepatol 2021;6:24.

2. Linenberger M, Fertrin KY. Updates on the diagnosis and management of the most common hereditary porphyrias: AIP and EPP. Hematology Am Soc Hematol Educ Program 2020;2020:400-10.

3. Takata T, Kume K, Kokudo Y, et al. Acute Intermittent Porphyria Presenting with Posterior Reversible Encephalopathy Syndrome, Accompanied by Prolonged Vasoconstriction. Intern Med 2017;56:713-7.

4. Agarwal S, Habtemarium B, Xu Y, et al. Normal reference ranges for urinary $\delta$-aminolevulinic acid and porphobilinogen levels. JIMD Rep 2020;57:85-93.

5. Marsden JT, Rees DC. Urinary excretion of porphyrins, porphobilinogen and $\delta$-aminolaevulinic acid following an attack of acute intermittent porphyria. J Clin Pathol 2014;67:60-5

6. Meersseman W, Cassiman D, Goossens W, et al. An unusual cause of syndrome of inappropriate antidiuretic hormone secretion. Acta Clin Belg 2008;63:277-80.

7. Willandt B, Langendonk JG, Biermann K, et al. Liver Fibrosis Associated with Iron Accumulation Due to LongTerm Heme-Arginate Treatment in Acute Intermittent Porphyria: A Case Series JIMD Rep. 2016;25:77-81. 